\title{
Debugging pathogens
}

\section{By Lauren Martz, Staff Writer}

A paper published in Science identifies how certain opportunistic pathogens-including Pseudomonas aeruginosa-attenuate the host innate immune response with $\mathrm{C} 12$, a quorum-sensing and immunomodulatory compound synthesized by certain bacteria. ${ }^{1}$ Although the host receptor for $\mathrm{C} 12$ remains unknown, the group at The Scripps Research Institute did show that the molecule disrupts NF- $\mathrm{\kappa B}$ signaling.

The role of $\mathrm{N}$-(3-oxo-dodecanoyl) homoserine lactone (C12; 3oxo- $\mathrm{C}_{12}$-HSL; PAI-1; OdDHL) -or its receptor-in the NF- $\mathrm{\kappa B}$ pathway has some researchers interested in blocking the compound as a new way to treat infection, but others are wary of triggering too much inflammation as a result of increased NF- $\mathrm{\kappa B}$ activity.

The transcription factor NF- $\mathrm{KB}$ is a cornerstone of the innate immune system..$^{2}$ It is activated when toll-like receptor-4 (TLR4) recognizes pathogen-associated molecular pat-

terns (PAMPs) of infectious agents, such as lipopolysaccharide (LPS) from Gram-negative bacteria. Once activated, NF- $\mathrm{KB}$ induces genes that encode inflammatory cytokines.

In the Science article, Richard Ulevitch and colleagues at Scripps showed that secretion of $\mathrm{C} 12$ may be used by certain bacteria, including P. aeruginosa, to disrupt NF- $\mathrm{KB}$ signaling and, consequently, lower the immune system's efficiency.

The paper builds on previous work from the same lab showing that disruption of quorum-sensing signaling can control infection. ${ }^{3}$ Quorum sensing is a process of communication between bacteria that is carried out by the secretion of small diffusible molecules such as C12.

Ulevitch, who has retired from Scripps, is corresponding author on the paper and maintains a lab at the institute as professor of immunology and chairman emeritus of the immunology department. He is also a venture partner at $5 \mathrm{AM}$ Ventures.

In in vitro studies with bone marrow-derived macrophages, the authors showed that secretion of C12 by $P$. aeruginosa disrupted NF$\kappa \mathrm{B}$ signaling. Exposure to Salmonella typhimurium and Staphylococcus aureus, neither of which secrete C12, did not affect NF-KB signaling.

LPS-induced expression of NF- $\mathrm{KB}$-regulated proinflammatory genes was also lower when the cells were exposed to both C12 and LPS, compared with exposure to LPS alone. Mouse studies confirmed the in vitro results and showed that LPS-induced NF-KB signaling was "significantly suppressed by C12," according to the authors.

"These findings could help to better understand why the immune system is not able to cope with persistent infection under certain circumstances, for example, in the lungs of cystic fibrosis patients or in chronic nonhealing wounds," said Aldo Ammendola, CSO of infectious disease company QuoNova Europe GmbH. "It may support the design of novel anti-C12 approaches."

\section{Using the target}

In addition to helping understand how pathogens survive, Steven Opal, professor of medicine and infectious diseases at Brown University Medical School, told SciBX that the Science paper paves the way to elucidating how anti-C12 therapeutics could be used.

"Compounds targeting C12 could definitely be used with antibiotics because they could repair the host response to bacterial challenge," he said. "C12-targeting compounds could be used for patients with severe infections and could be administered along with antibiotics to eliminate the bacteria and control the host inflammatory response."

QuoNova, which is developing quorumsensing blockers (QSBs), has already looked into how such compounds, including compounds targeting $\mathrm{C} 12$, can complement antibiotics to treat persistent infections.

Ammendola told SciBX the company has demonstrated how QSB-treated cells are much more susceptible to conventional antimicrobials than untreated cells. "QSB and antibiotic combinations significantly increased antimicrobial activity compared to antibiotics used alone," he noted.

QuoNova’s QSBs are in preclinical development to treat infections. Ammendola said a clinical candidate has been selected, and the company expects to conduct GMP and toxicity studies on the compound within the next 12 months.

\section{Inflammation balancing act}

Although the Science paper demonstrates that C12 disrupts normal immune signaling, it isn't yet clear how best to target it. Some infectious disease companies think it will be a balancing act, as too much activation of NF- $\mathrm{KB}$ can lead to runaway inflammation.

The expectation is that blocking C12's receptor is the likely angle that future studies will take. The challenges with this approach are twofold. First, the receptor needs to be identified. Second, it is possible that blocking the receptor could affect the inflammatory process in unanticipated ways.

Overall, however, researchers polled by SciBX expect that hitting C12 or its receptor will not be any worse than blocking anything else involved in the NF- KB pathway.

"The question is how to eliminate C12 to avoid its modulation of 


\section{TARGETS \& MECHANISMS}

the innate immune response. This can be done either by regulating the bacterial target, or addressing the human receptor, which has yet to be defined," said Daniel Vitt, CSO of 4SC AG.

4SC has two NF- $\mathrm{KB}$ inhibitors in preclinical development: SC71492 to treat rheumatoid arthritis (RA) and irritable bowel disease (IBD), and SC75741 to treat influenza virus.

Like Vitt, Ulevitch thinks finding the host target of C12 is a key next step.

"We have multiple ways to target $\mathrm{C} 12$, but we need to know how they impact the physiological mechanisms," he said. "Therefore, we first want to know the receptor for $\mathrm{C} 12$ in the mammalian cell and more about its signaling pathway. Then, because these were cell-based, mechanistic studies, the research needs to be moved into animals. We are in the selection process of choosing the best animal-infection model."

Regardless of the specific host target of C12, Ammendola noted that "developing drugs that directly interact with the human immune system-especially if it relates to a major signaling system like $\mathrm{NF}-\mathrm{\kappa B}$ - always raises safety issues and questions. R\&D has to address the potential immune system issues early in the drug development process."

"When you are interfering with a highly conserved defense strategy and begin perturbing the system, you put the host at risk of an improperly regulated immune system," said Opal.

Markwin Veders, VP of R\&D at AM-Pharma B.V., noted that increased inflammatory responses are associated with inflammatory disorders and septic shock.
AM-Pharma's bovine alkaline phosphatase, an enzyme that removes LPS, is in Phase IIa testing to treat sepsis.

Veders noted other issues to be cleared up in the drug development process for $\mathrm{C} 12$ therapeutics.

"It needs to be established how much $\mathrm{C} 12$ needs to be inactivated in order to obtain a therapeutic beneficial effect during infection. Is $25 \%$ reduction sufficient or is $90 \%$ inactivation required?" he said.

In addition, Veders said, "specific targeting is always a challenge. You need to know how to get the compound in sufficient quantities at the site of infection."

Ulevitch told SciBX that the researchers have filed a patent application covering the findings, and the IP is available for licensing.

\section{REFERENCES}

1. Kravchenki, V. et al. Science; published online June 19, 2008; doi:10.1126/science.1156499

Contact: Richard Ulevitch, The Scripps Research Institute, La Jolla, Calif. e-mail: ulevitch@scripps.edu

2. Bohuslav, J. et al. J. Clin. Invest. 102, 1645-1652 (1998)

3. Park, J. et al. Chem. Biol. 14, 1119-1127 (2007)

COMPANIES AND INSTITUTIONS MENTIONED

4SC AG (Xetra:VSC), Martinsried, Germany

5AM Ventures, Menlo Park, Calif.

AM-Pharma B.V., Bunnik, the Netherlands

Brown University Medical School, Providence, R.I.

QuoNova Europe GmbH, Martinsried, Germany

The Scripps Research Institute, La Jolla, Calif. 